\title{
Arte y política después del 2001. La experiencia estética del colectivo de educación y recreación popular "La Oruga", en la ciudad de Buenos Aires*
}

Art and politics after 2001. The aesthetic experience of the collective of education and popular recreation "La Oruga" in the city of Buenos Aires

\author{
Sebastián Levalle**
}

\section{Resumen}

A principios del 2004 surge el colectivo "La Oruga", una experiencia de educación y recreación popular que se desarrolló fundamentalmente en una plaza del barrio porteño de Balvanera en la capital argentina. En este trabajo me propongo abordar la experiencia de La Oruga entre el 2004 y el 2010, de la cual formé parte, desde una mirada estética. Sostendré que la actividad del colectivo puede concebirse como una ocupación artístico-cultural del espacio público orientada a la creación de nuevas relaciones sociales. En la experiencia de la Oruga se desarrolló una tensión que sus integrantes concebimos como una oposición entre "el arte" -o "lo cultural" - y "la política". Voy a afirmar que el diálogo entre los intereses barriales y los de la organización se tradujo en formas "negociadas" de acción político-cultural, movilizando productivamente aquella tensión original y evitando una subordinación lineal del arte a la política.

\section{Abstract}

In early 2004 appears the collective "The Caterpillar", an experience of popular education and recreation that has been mainly developed in a square in the neighborhood of Balvanera in the Argentinian capital. In this paper I propose to address the 
experience of The Caterpillar between 2004 and 2010, of which I was part, from an aesthetic look. I will argue that activity performed by the collective can be seen as an artistic and cultural occupation of the public space oriented to the creation of new social relations. In the experience of The Caterpillar had developed a tension that its members had conceived as an opposition between "the art" - or "the cultural"- and "the politics". I will argue that the dialogue between neighbor's interests and those of the organization resulted in "negotiated" forms of political and cultural action, productively mobilizing that original tension and avoiding a linear subordination of art to politics.

\section{Palabras clave}

Política - estética - movimientos sociales.

\section{Keywords}

Politics - aesthetic - social movements.

\section{El arte postcrisis y la emergencia de La Oruga}

A mis compañerxs de La Oruga

La crisis que atravesó la Argentina en diciembre del 2001 configuró un nuevo tiempo de la política. Como corolario de las medidas neoliberales que habían sido implantadas desde la última dictadura militar y profundizadas durante los gobiernos de Carlos Saúl Menem (1989-1999), hacia finales de los años 1990 se multiplicaron las organizaciones populares. Aparecieron nuevos actores y nuevas voces en la escena política, como las asambleas populares, en las que los vecinos se reunían a debatir las problemáticas barriales, los movimientos de trabajadores desocupados (MTD), que reclamaban trabajo digno y generaban microemprendimientos en los barrios, o las empresas recuperadas por sus propios trabajadores y puestas en funcionamiento bajo su control en ausencia de los patrones. Estos movimientos, entre otros, reconfiguraron el terreno de lo que se define como "común", como perteneciente a todos. Emergió con la crisis un nuevo "reparto de lo sensible" (Rancière, 2011), es decir, una desarticulación entre las capacidades de cada individuo y los lugares asignados socialmente. El tiempo se volvió colectivo y se politizó a partir de las acciones político-sociales de estos nuevos actores. ${ }^{1}$ Los vecinos y los trabajadores desocupados se asumieron como sujetos de una política que se desplegaba "entre la ruta y el barrio" (Svampa y Pereyra, 2003), lejos

\footnotetext{
${ }^{1}$ Siguiendo a Rancière (2011: 34) podemos afirmar que se trata de una politización del tiempo: "La política ocurre cuando aquellos que "no tienen" el tiempo se toman este tiempo necesario para plantearse como habitantes de un espacio común y para demostrar que su boca emite también una palabra que enuncia lo común y no solamente una voz que enuncia dolor."
} 
de las instituciones desprestigiadas del Estado. Durante todo el 2002 estos movimientos sociales ocuparon el espacio público combinando una diversidad de repertorios de acción. La consigna "piquete y cacerola, la lucha es una sola" sintetizaba esa sensación de destino común instaurando una beligerancia popular inédita desde el retorno de la democracia.

El nuevo tiempo de la política fue también un nuevo tiempo del arte argentino. La constatación de un futuro político completamente imprevisible, basta recordar la sucesión de cinco presidentes en apenas diez días, sumada al crecimiento de las organizaciones populares que disputaban el espacio público a diario, configuraron un escenario propicio para la renovación cultural. Es esta "apertura de los horizontes" (Anderson, 1993) ${ }^{2}$, la que habilita un nuevo tiempo para la producción y recepción del arte argentino, reinstalando el viejo debate sobre la autonomía del arte y el compromiso del artista (Paredes, 2011). La crisis produjo una expansión de espacios artísticos y de colectivos culturales. Argentina Arde, el Taller Popular de Serigrafía, el Grupo de Arte Callejero, entre muchos otros, apostaron por un nuevo modo de hacer arte, basado en la producción colectiva y en el uso de nuevos materiales (Giunta, 2009). A su vez, algunos de los movimientos sociales surgidos en este momento inauguraron espacios artísticos propios, desde los centros culturales en las fábricas recuperadas hasta los talleres de arte de las asambleas y los MTD. La redistribución de los lugares y las identidades, tensionó las fronteras entre el arte y la política o, más bien, volvió la mirada una vez más hacia las "políticas de la estética" (Rancière, 2011). Las formas en las que las prácticas artísticas intervienen en el reparto de lo sensible y redefinen aquello que designamos como perteneciente al espacio de lo "común" retornaron al centro del debate.

El "colectivo autónomo de educación y recreación popular La Oruga" es un producto de la crisis del 2001. Los integrantes del colectivo, entre 10 y 15 personas, comenzamos formando parte de una asamblea popular de vecinos de Balvanera surgida en plena crisis. Durante el 2004 quienes luego integraríamos la organización trabajamos semanalmente en una escuela pública del barrio. Este espacio de trabajo, que la institución escolar y los estudiantes denominaban "La Asamblea", tenía por objetivo construir una instancia democrática de toma de decisiones -tal como lo hacían las asambleas populares en los barrios de la ciudad de Buenos Aires- con chicos de los tres sextos grados. Hacia mediados de año se inaugura los días sábados por la tarde generalmente entre las 13 y las $18 \mathrm{hs}$ - el espacio de trabajo en la plaza ubicada en la intersección de las calles México y Jujuy. En este momento quienes llevábamos adelante la comisión de educación de la asamblea decidimos escindirnos conformando

\footnotetext{
${ }^{2}$ Comparando la situación del Tercer Mundo con la de los países centrales Anderson (1993: 16) comenta: "Lo que caracteriza a la situación típica del artista contemporáneo en Occidente es, por el contrario, el cierre de los horizontes: sin un pasado apropiable, o un futuro imaginable, en un presente interminablemente repetido."
} 
La Oruga. La organización se identificaba con ciertos principios compartidos por varios de los movimientos sociales de inicios de la década del 2000 (Svampa, 2008; Zibechi, 2003): la independencia partidaria, la horizontalidad en la toma de las decisiones, la autonomía, el enfoque de la educación popular, la construcción de poder popular desde los barrios. El colectivo se financiaba fundamentalmente con aportes de sus integrantes y con dos o tres peñas folklóricas anuales. No se recibían fondos de ninguna institución pública ni privada y todas las actividades barriales eran gratuitas.

El trabajo barrial incluía una serie de actividades semanales en la plaza orientadas a la conformación de un espacio de encuentro y de problematización de la realidad de Balvanera y San Cristóbal, sus dos barrios de influencia. Los vecinos que se encontraban en la plaza eran invitados a formar parte de las iniciativas del colectivo. Las actividades se difundían mediante volantes, por Internet, con afiches en algunas facultades y con el periódico barrial que se entregaba en las casas de varios vecinos. Entre estas actividades se cuenta una variedad de talleres que abordaban el deporte, la recreación, el apoyo escolar, la música, el periodismo comunitario, las artesanías, la alfabetización, la lectura colectiva, el dibujo y la expresión plástica. A su vez, desde el 2005 se instala en la plaza una biblioteca popular y un encuentro de lectura. Durante los años 2007 y 2008 el colectivo incorporó el trabajo sobre la vivienda, buscando evitar los desalojos de los hoteles ilegales y las casas tomadas del barrio. Hacia el 2010 se inician una serie de intervenciones en la plaza junto con los adolescentes, instalándose espacios deportivos y de juegos para los niños y se multiplican las instalaciones artísticas. Por otra parte, la organización desarrolló actividades lúdicas y artísticas en marchas, en movilizaciones y en algunos congresos académicos. La Oruga se desarticuló hacia fines de octubre del 2010. Varios de sus integrantes conformaron Radio Semilla, una radio comunitaria que actualmente se encuentra en la empresa recuperada IMPA en el barrio porteño de Almagro. ${ }^{3}$

En este trabajo me propongo abordar la experiencia de La Oruga entre el 2004 y el 2010 desde una mirada estética. Me interesa analizar algunas experiencias estéticas del colectivo y a la vez reflexionar acerca del lugar que le asignábamos a las prácticas artísticas. Para ello analizaré el acervo documental que produjo el grupo: planificaciones y crónicas de los talleres, minutas de las reuniones anuales de balance, los nueve números del periódico de la organización, y correos y documentos internos. Al conjunto de fuentes documentales añadiré mis propios recuerdos en una suerte de acercamiento autoetnográfico. ${ }^{4}$ Sostendré que la actividad del colectivo puede concebirse como una ocupación artístico-cultural del espacio público orientada a la creación de nuevas relaciones sociales. En primer lugar revisaré las premisas y los

\footnotetext{
${ }^{3}$ Más información sobre Radio Semilla en su sitio virtual: http://www.radiosemilla.com.ar

${ }^{4}$ La autoetnografía es una opción metodológica y una forma de escritura en la cual el investigador se analiza a sí mismo como si estudiara a un "otro". Se configura entonces como un estudio que despliega múltiples planos de conciencia, conectando lo personal con lo cultural (Ellingston y Ellis, 2008).
} 
objetivos del trabajo de la organización para poder comprender el marco en el que se inscribieron las prácticas estéticas. Luego describiré varias actividades artísticas llevadas a cabo entre el 2004 y el 2010. En tercer lugar analizaré las prácticas estéticas del colectivo intentando comprender su sentido y su articulación con las iniciativas político-sociales del grupo. En la experiencia de la Oruga se desarrolló una tensión que sus integrantes concebimos como una oposición entre "el arte" -o "lo cultural"- y "la política". Esta tensión será analizada en el apartado final. Afirmaré entonces que el diálogo entre los intereses barriales y los de la organización se tradujo en formas "negociadas" de acción político-cultural, movilizando productivamente aquella tensión original y evitando una subordinación lineal del arte a la política.

\section{Objetivos y ejes de trabajo de La Oruga: educación popular, recreación popular y espacio público}

Los integrantes de La Oruga pensábamos nuestro trabajo en torno a tres ejes fundamentales: la educación popular, la recreación popular y la ocupación del espacio público. La educación fue concebida por el colectivo como una herramienta para el

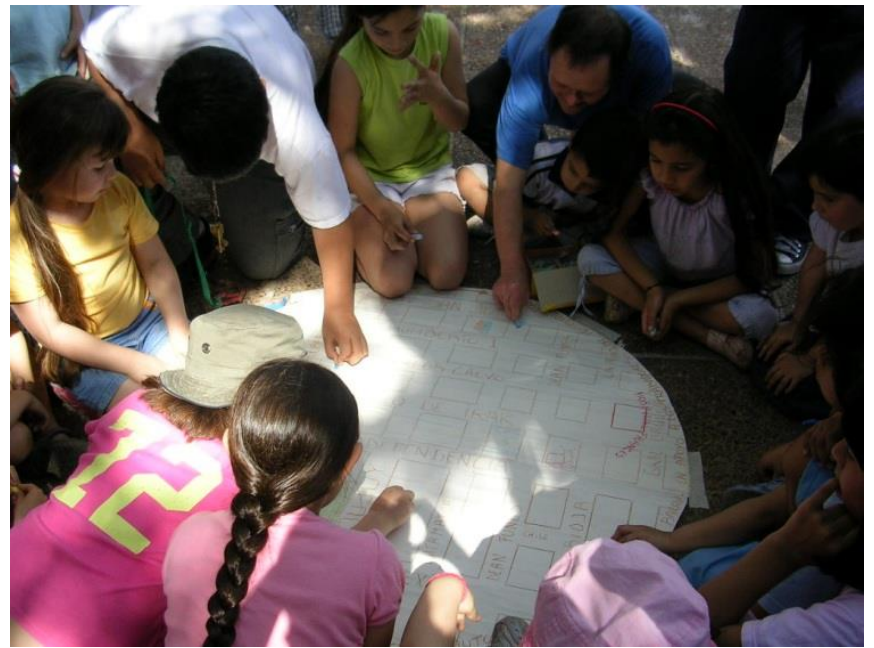

Ilustración 1. Actividad de recreación popular en la plaza. 2006. cambio social. Partiendo desde la concepción de la educación popular, fundamentalmente de los escritos del pedagogo brasileño Paulo Freire, se pretendía construir conocimientos desde la realidad de los barrios de Balvanera y San Cristóbal y con la participación de sus habitantes. El proceso educativo era pensado como un diálogo permanente entre el colectivo y los vecinos del barrio. Este diálogo estaba orientado hacia la conformación

de una visión crítica de la realidad social sobre la cual se construirían las herramientas necesarias para encarar la transformación de las problemáticas comunes. La esperanza de una buena parte de los integrantes de La Oruga era volverse prescindibles al conseguir que los mismos vecinos generasen las instancias de organización que creyeran necesarias. La educación funcionó como un eje transversal al conjunto de actividades de la organización. Más allá de las actividades netamente educativas, como los talleres de alfabetización y de apoyo escolar, todas las acciones del colectivo fueron pensadas bajo la premisa de construir conocimiento y conciencia crítica a partir del diálogo con los distintos sectores del barrio. 
Una buena parte de las actividades de La Oruga se enfocaban a una población infantil o juvenil. Este hecho determinó, en parte, que el juego se incorporara como un elemento central a la hora de planificar las actividades. No se trataba simplemente de jugar sino de incorporar el juego como una propuesta pedagógica. Se comenzó a trabajar sistemáticamente con dinámicas de recreación educativa con niños $y$, en menor medida, con adultos. En muchas oportunidades los juegos incorporaron contenidos políticos, funcionando como disparadores para el trabajo de educación popular. Así surgió lo que denominamos "recreación popular", una suerte de combinación de técnicas de educación popular y de recreación. ${ }^{5}$

El tercer eje de trabajo fue el espacio público. Entre los objetivos fundamentales de la organización figuraba la creación de nuevas relaciones sociales en los espacios comunes (La Oruga, 2007b). La organización nunca contó con un local propio, de hecho, los integrantes del colectivo identificábamos al espacio público como la sede de la organización, en buena medida esto se debió a la decisión de ocupar la plaza y construir nuevas relaciones sociales desde este ámbito.

"Trabajamos en el espacio público porque nos resulta fundamental recuperarlo como lugar de lucha, memoria y resistencia, para desde ahí poder, entre todos, empezar a caminar hacia una sociedad distinta" (Balance anual del periódico barrial Qué lo Parió!, 2009).

El colectivo concebía a la política estatal sobre el espacio público implementada desde fines de la década de 1990 como una política que hacía énfasis en el control de la población. A nuestro entender el control se materializaba en la aplicación de lógicas del espacio privado en el espacio público, tales como las rejas perimetrales, las cámaras de seguridad y la presencia de guardianes en las plazas. Estas medidas convertían a los espacios públicos en espacios excluyentes, desplazando y ocultando las problemáticas sociales. Por otra parte, las modificaciones de las plazas se llevaban adelante sin consultar a los vecinos y en muchos casos estaban animadas más por las urgencias electorales que por las necesidades del barrio. La Oruga planteaba entonces que la política estatal concebía a los espacios públicos como espacios de tránsito y no como lugares de encuentro y socialización.

"Las plazas hoy son jardines, no se puede nada más que caminar, ni llevar al perro ni jugar a nada. Los chicos cada vez juegan más en ámbitos privados y reducidos, con gente exactamente igual a ellos." (...) "¿a quién se le va a ocurrir en capital federal jugar al fútbol en un lugar que no sea pago, en un lugar que no sea una canchita de fútbol 5 ? En esas canchitas no se forman grupos, los grupos ya se conocen de antes" (Correo interno. 2004).

\footnotetext{
${ }^{5}$ La propuesta de la recreación popular fue presentada en el Cabildo de Juego y Cultura realizado los días 17 y 18 de septiembre del 2005 en el Instituto de Tiempo Libre y Recreación, Buenos Aires, Argentina.
} 
"La temática de Espacio Público, fue abordada desde la perspectiva inicial de su conformación desde el punto de vista teórico, como un espacio de encuentro, de reconocimiento, como el lugar donde gestar las relaciones humanas, desde una perspectiva socio - política, donde los diferentes pueden convivir y compartir" (Crónica encuentro de lectura sobre espacio público en plaza Martín Fierro. 2009).

La propuesta de la organización consistía entonces en recuperar el espacio público como un ámbito de socialización en la diversidad. Se buscaba generar en la plaza las instancias educativas o dialógicas necesarias para que el barrio logre debatir las problemáticas comunes y generar instancias de organización colectiva (La Oruga, 2007b). La mayor parte de las actividades del colectivo se enmarcaban en estos tres pilares: la educación popular, la recreación popular y la construcción de un ámbito de socialización en el espacio público. Sin embargo, como intentaré mostrar en el apartado siguiente, casi todas ellas involucraban un importante despliegue estético.

\section{La Oruga como ocupación artístico-cultural del espacio público}

El debate sobre la legitimidad y la eficacia del arte cambia de escenario en la crisis del 2001. Los partidos políticos y el aparato estatal sufren un proceso de acelerada

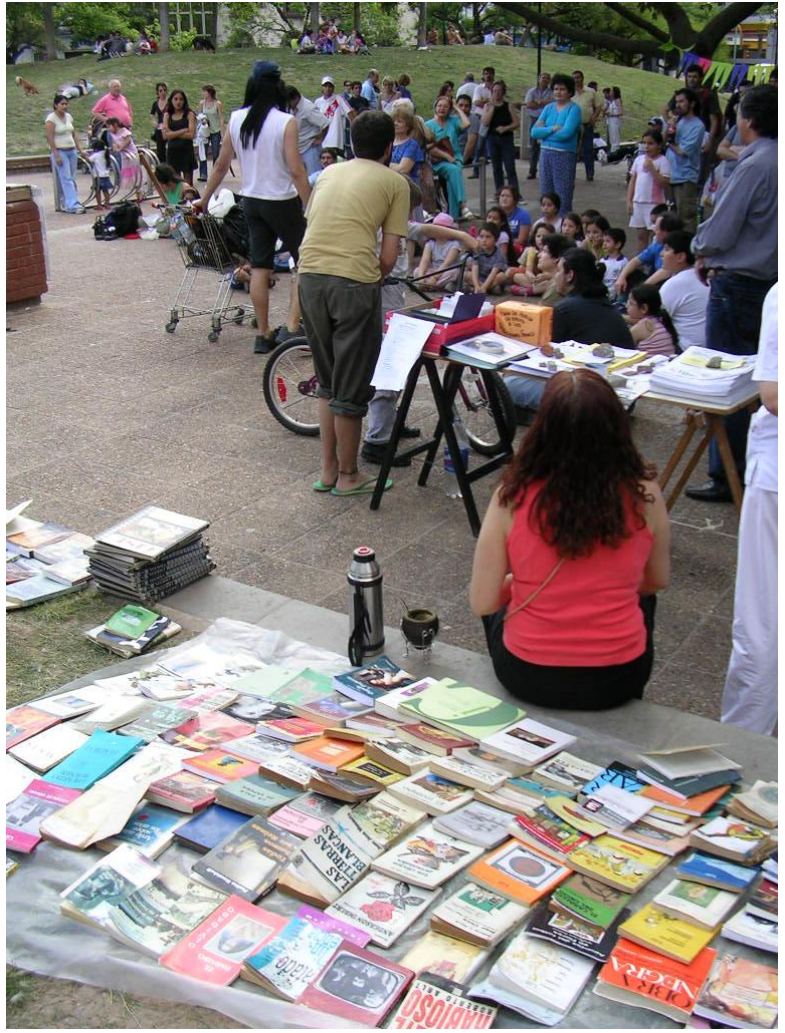

Ilustración 2. Biblioteca de La Oruga. 2006. deslegitimación. Andrea Giunta afirma que durante los primeros años de la crisis los artistas solían presentarse a sí mismos como integrantes de un colectivo. Pareciera que la legitimidad del artista se definía parcialmente por esta condición asociativa y no ya únicamente por la circulación en los circuitos tradicionales. La eficacia se jugaba entonces en "el tratamiento horizontal a la hora de analizar las propuestas y, al mismo tiempo, [en] la adecuación de esas propuestas con los reclamos colectivos" (citada en Gago, 2009). En este puente entre las propuestas artísticas y los reclamos colectivos es posible comenzar a pensar la práctica estética de La Oruga. La dimensión estética no figuraba en ninguno de los objetivos del grupo ya que nos asumíamos como militantes políticos que apostaban a la educación y a la recreación popular para problematizar la realidad barrial (La Oruga, 2007). Pero aunque fue subestimado por la mayor parte de los 
integrantes del colectivo, el arte resultó un componente importante de las actividades de La Oruga.

Imaginemos una tarde de sábado cualquiera del año 2009 en la plaza de México y Jujuy. La jornada comenzaba colgando dos banderas con el nombre y el logo de la organización sobre la reja que separa la plaza de una escuela que comparte la misma manzana. Una oreja pintada sobre tela sin ninguna inscripción era colocada en el centro de esta reja. Acto seguido algunos de los integrantes del grupo se dirigían a la cooperativa textil "18 de Noviembre", la antigua "Brukman" recuperada por sus trabajadoras, donde se guardaban los libros de la biblioteca popular. Los cerca de mil títulos que componían la biblioteca se ubicaban con sus portadas hacia arriba sobre el pasto en un desfile que se extendía varios metros. Este despliegue, en el que participaban algunos vecinos, ritualizaba el inicio de las actividades. La biblioteca estaba encabezada por una mesa donde se encontraban algunos folletos de la organización junto a las fichas de socios, a los que se les solicitaba de forma voluntaria su nombre y una dirección.

A un lado de la biblioteca se ubicaba la juegoteca, un cajón de madera que contenía elementos deportivos y juegos de mesa de libre acceso. En distintos lugares de la plaza el colectivo había pintado juegos tradicionales, como la rayuela. También se había realizado, con la participación de los vecinos, una cancha de básquet, una de fútbol y una de fútbol-tenis. Para la construcción de la cancha de fútbol la organización había coordinado jornadas de trabajo a lo largo de varios meses con los adolescentes que solían acudir a la plaza de forma regular. Un cartel colgaba en uno de los costados de la plaza señalando el nombre elegido por los adolescentes para su cancha de fútbol: "La Cabral. Cancha de Futbol de los pibes-as de la plaza". En la reja lindante con la escuela colgaban además dos pinturas realizadas por niños de entre 6 y 12 años y en las baldosas de la plaza flameaban los dibujos de las banderas de las diversas nacionalidades de los asistentes a los talleres. Una vez instalada la biblioteca comenzaban a funcionar los talleres, la juegoteca y un encuentro de lectura, extendiéndose los espacios de reunión a lo ancho de toda la plaza.

De este modo la plaza resultaba intervenida por una diversidad de actividades que compartían ciertas premisas típicas del arte relacional contemporáneo, como la participación activa y la dimensión lúdica. Pero dentro del conjunto de propuestas de la organización algunas se enfocaron más específicamente en el campo estético. A continuación me voy a detener en dos tipos de intervenciones artísticas que desarrolló el colectivo. Por una parte comentaré el trabajo realizado en los talleres de expresión plástica y de dibujo y pintura. Por la otra, voy a describir una serie de instalaciones artístico-culturales donde se combinaron diversos recursos y técnicas de intervención. El taller de expresión plástica para niños de entre 4 y 6 años fue una de las primeras actividades desarrolladas en la plaza. Funcionó desde el 2004 y hasta el 2009 con una frecuencia semanal. Este taller contó con una asistencia regular de alrededor de veinte 
niños, en varias ocasiones con sus padres que eran convocados para compartir algunas

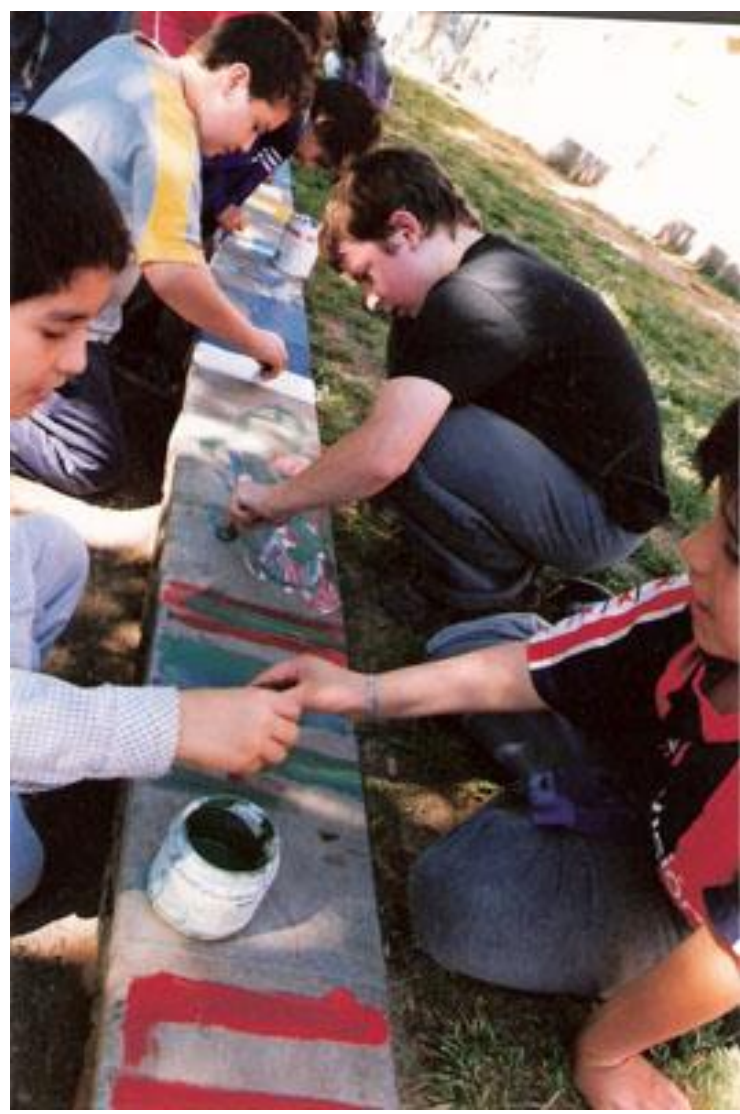

Ilustración 3. Taller de expresión plástica. 2006. reflexiones durante el cierre de la actividad. Se realizaron collages, murales, dibujos, máscaras, maquetas, muñecos gigantes, títeres, rompecabezas y otros juegos intervenidos por los chicos, combinando una diversidad de soportes y de materiales de trabajo. El taller buscaba alcanzar una construcción colectiva a partir de las producciones individuales. En varias ocasiones se comenzaba con una instancia de pintura libre y luego se integraban los distintos trabajos en una síntesis que generalmente quedaba instalada en la plaza durante la semana (Planificaciones 2005/2006). Desde el 2008 se sumaron la música y la recreación de una forma más sistemática y se buscó incorporar temáticas políticas o sociales al trabajo del taller tanto en la actividad con los chicos como en el cierre con los padres, a quienes se intentó incorporar con mayor énfasis (Balance Taller de Expresión Plástica, 2009). ${ }^{6}$

En algunas actividades que realizaba La Oruga en función de problemáticas barriales o de fechas conmemoratorias se ponían en juego una serie de recursos artísticos de un modo diferente al que acabo de reseñar. A continuación me detendré en tres de estas actividades, dando cuenta del despliegue estético que ellas involucraron. El aniversario del último golpe de Estado argentino, el 24 de marzo, fue una fecha de especial importancia para el colectivo. Esta conmemoración fue concebida como una oportunidad para trabajar la memoria en el espacio público y, al mismo tiempo, recordar a los 30.000 detenidos-desaparecidos por el terrorismo de Estado mediante el juego. El conjunto de actividades fue variando y complejizándose desde el 2004 hasta el 2009. Generalmente se trabajó en dos momentos, por un lado se desarrollaron

\footnotetext{
${ }^{6}$ El taller de dibujo y pintura para adolescentes y adultos nace en el 2006 en buena medida como una forma de incorporar a los padres durante la actividad de los chicos. Participaron de este taller unas diez personas. Aquí también se intentó fomentar el trabajo colectivo, a lo que se agregó la interacción con los vecinos del barrio mediante el trabajo artístico. Existía una expectativa de que este espacio se convirtiera en un grupo de intervención artística en el barrio, aunque esto no sucedió (Balance Taller de Dibujo y Pintura 2006).
} 
diversas dinámicas en la plaza de las calles México y Jujuy, y por el otro, se utilizaba una técnica de recreación para acompañar a la tradicional marcha encabezada por los organismos de derechos humanos desde el Congreso hasta la Plaza de Mayo.
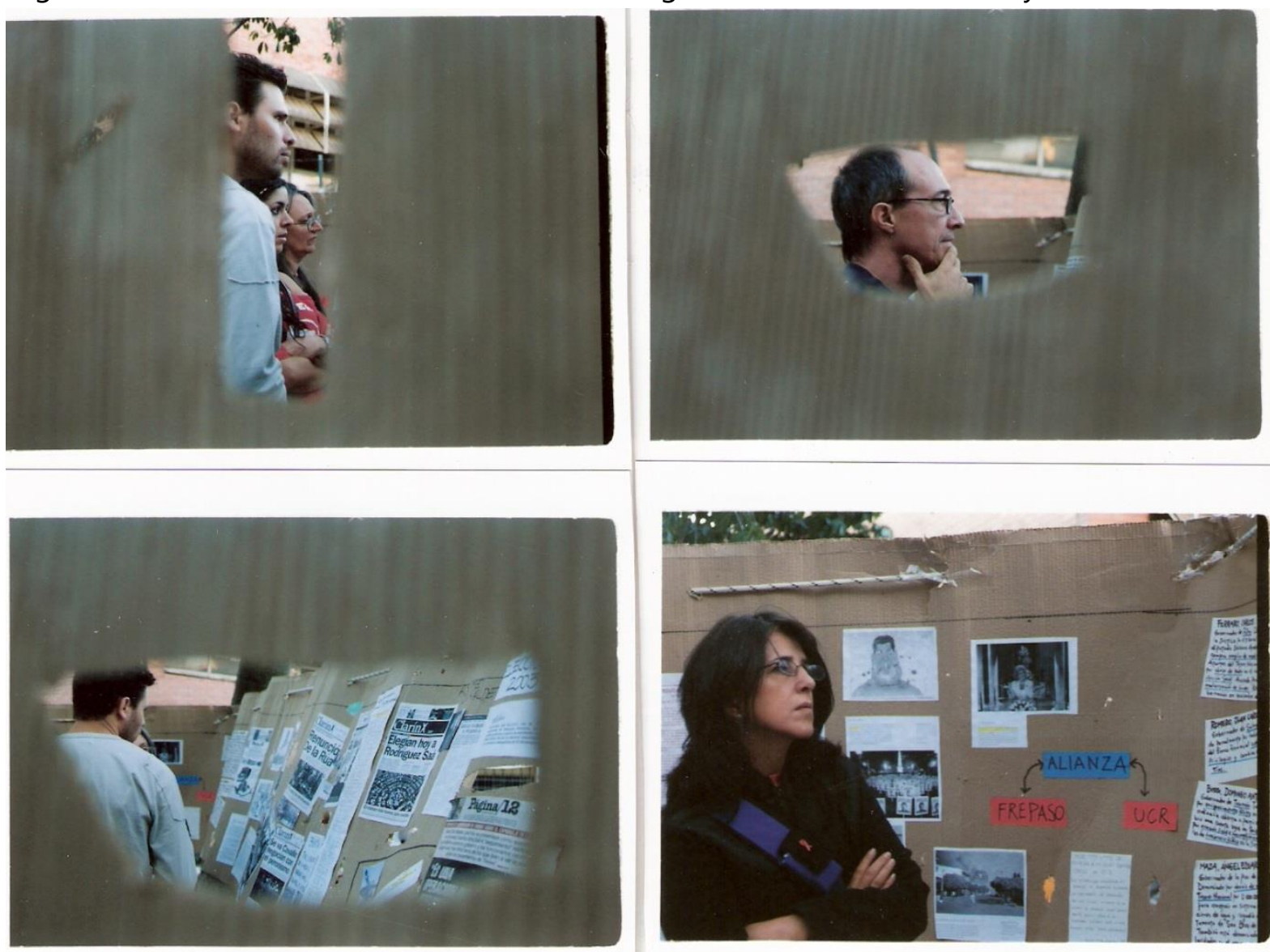

Ilustración 4. Triángulo de la memoria. 2006.

En la plaza de Balvanera se colgaba un cartel con la leyenda: "24 de marzo de 1976 24 de marzo de [año de realización de la actividad], 30.000 desaparecidos, su lucha continúa" acompañado de una pintura en la que se retrataba a varios pañuelos que representaban a las Madres de Plaza de Mayo juzgando a un gorro militar. ${ }^{7}$ En el centro del espacio se instalaba una estructura que llamábamos "Triángulo de la Memoria". Se trataba de una estructura triangular de papel corrugado que oficiaba de soporte de una línea del tiempo en la que se incluían recortes de diario, gráficos, estadísticas y fotografías desde los años 1950 hasta el presente. El triángulo permanecía en la plaza durante toda la actividad, ofreciendo una experiencia muy personal ya que por su

\footnotetext{
${ }^{7}$ Desde el 2009 se incorporaron otros recursos visuales como un mapa de la argentina conformado a partir de fotografías de detenidos-desaparecidos sobre el cual sobrevolaba un avión militar, representando los vuelos que utilizaban los militares para arrojar a los detenidos al Río de la Plata conocidos como "vuelos de la muerte". Estos dispositivos eran confeccionados en su mayor parte por un artista plástico que formaba parte del grupo (ver apartado final).
} 
disposición se configuraba como un espacio cerrado. ${ }^{8}$ Al mismo tiempo los coordinadores de la actividad repartían una hoja a las personas que se encontraban en la plaza proponiéndoles que respondieran la siguiente pregunta: “¿cómo y cuándo te enteraste del último golpe militar?". Las respuestas eran pegadas en la parte de atrás del triángulo de la memoria.

Con los niños se desarrollaba una adaptación lúdica de una actividad conocida como

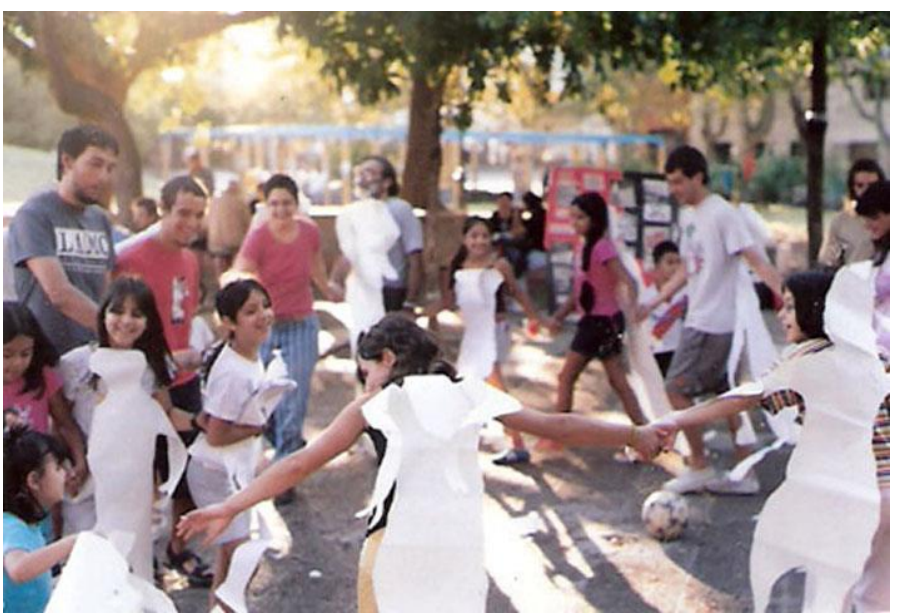

Ilustración 5. Siluetazo. 2005. "El Siluetazo", puesta en práctica por primera vez en 1983 durante la Tercera Marcha de la Resistencia por las Madres de Plaza de Mayo. Los chicos trabajaban en parejas. Uno se acostaba sobre un papel blanco y otro dibujaba la silueta que luego era recortada. Con las siluetas pegadas en la espalda comenzaban a jugar a distintos juegos cooperativos en ronda. Al jugar, las siluetas se ponían en movimiento. Con el baile de las siluetas buscábamos representar la presencia de los detenidos-desaparecidos en las nuevas generaciones. Así lo expresábamos en uno de los volantes que acompañaba las actividades:

"La construcción de las siluetas es un modo de reconstruir los lazos entre las generaciones que vino a romper la dictadura, es una forma de duplicar nuestra presencia logrando que los desaparecidos aparezcan. Con el siluetazo damos vida a los 30.000 detenidos-desaparecidos que faltan y que están adentro nuestro cuando tratamos de cambiar las cosas que nos duelen y cuando luchamos por un mundo mejor" (Volante del 24 de marzo del 2009).

Luego, los niños elegían la posición y el sitio de la plaza en el que querían dejar instaladas sus siluetas por el resto de la semana.

Al finalizar el siluetazo comenzaba el encuentro de lectura, una actividad de frecuencia quincenal que se desarrolló en la plaza desde el 2006 y que invitaba a los vecinos a compartir lecturas en voz alta. Para rememorar el golpe de Estado de 1976 se seleccionaban algunos libros de la biblioteca popular de la organización que abordaban el tema y se invitaba a algunas organizaciones de derechos humanos a participar.

\footnotetext{
${ }^{8}$ Así lo reflejan las crónicas de aquel entonces: "Era un momento muy extraño, al que daba pudor interrumpir con los anuncios míos de que pueden escribir en el papel. Cada vez que lo hacía tenía la sensación que interrumpía algo, la reflexión, el dolor, los recuerdos; me sentía de más, el impacto de la línea era suficiente..." (Crónica de la actividad del 24 de marzo del 2006)
} 
En la marcha convocada por los organismos de derechos humanos la organización intervenía poniendo en juego la dinámica de la cual surge su propio nombre. La técnica

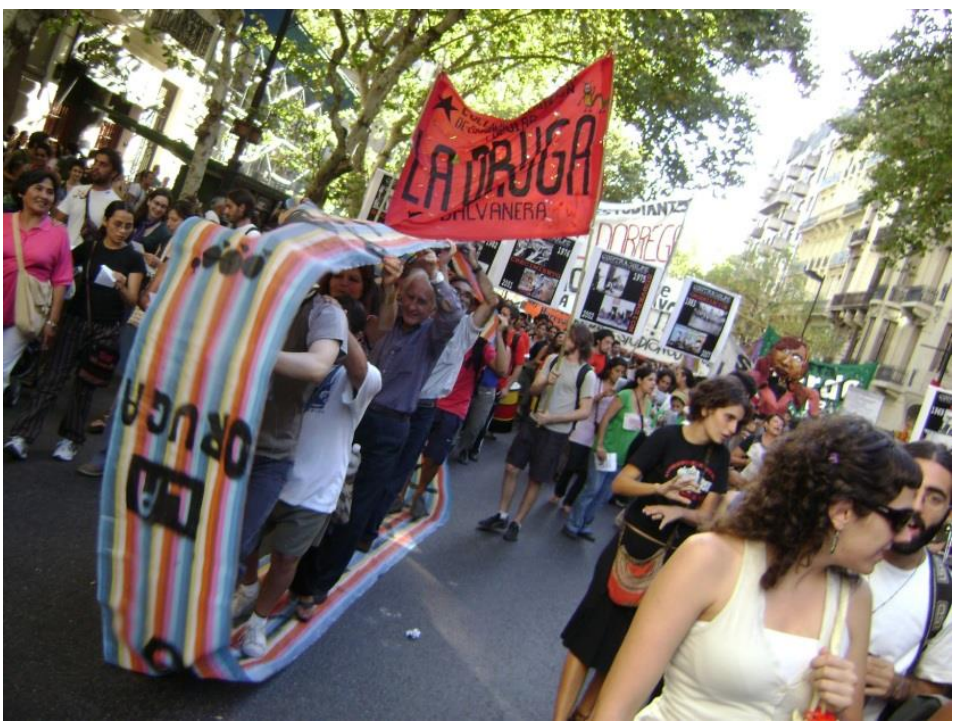

Ilustración 6. Marcha en oruga. 24/3/2008

consiste en caminar colectivamente adentro de una tela cosida en sus extremos. La tela se convierte entonces en la "oruga tanque", el dispositivo de transporte utilizado por vehículos pesados. Para lograr avanzar es necesario que la tela gire y para ello se requiere del caminar coordinado de todos los participantes. La oruga que llevábamos a la marcha tenía una inscripción que afirmaba: "seguimos caminando". El juego permitía incorporar a algunos niños que estaban marchando con sus padres pero también buscaba recuperar la alegría de la lucha por un mundo nuevo en una fecha cargada de dolor:

"Cada 24 de marzo, los que no olvidamos, los que no nos reconciliamos, salimos a la calle, porque creemos en el camino de la lucha. La oruga es una forma de andar este camino. Es una forma que intenta recuperar la alegría que trataron de callarnos y que alimenta nuestra construcción" (Volante repartido en la marcha del 24 de marzo del 2007).

De esta forma, intentábamos combinar el arte y el juego para potenciar el diálogo y la participación de los vecinos en la construcción de la memoria colectiva.

El 26 de junio del 2002, bajo el gobierno de Eduardo Duhalde, las fuerzas policiales asesinaron a Maximiliano Kosteki y Darío Santillán, dos trabajadores desocupados que participaban de una masiva manifestación en la estación de ferrocarriles de Avellaneda, en las afueras de la Ciudad de Buenos Aires. Desde el 2004 La Oruga participó en los actos conmemoratorios de este hecho, conocido como "La Masacre de Avellaneda", coordinando

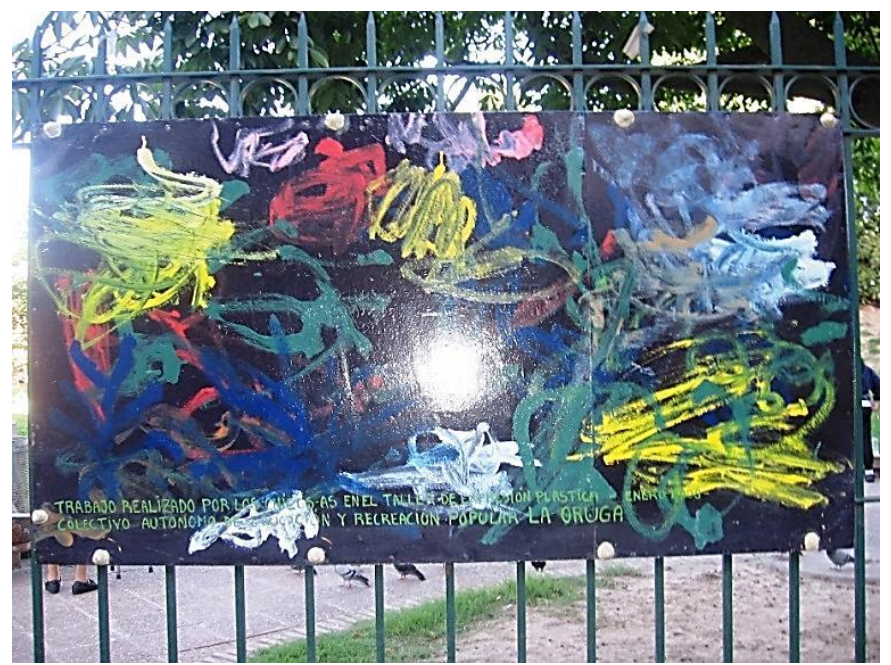

Ilustración 7. Obra colectiva del taller de expresión plástica emplazada en las rejas de la plaza de México y Jujuy. 2009. 
actividades plásticas para los niños de los movimientos de trabajadores desocupados. El lienzo pintado de forma libre en el 2004 por chicos de entre 2 y 6 años fue colocado en un bastidor y comenzó un ciclo de exposiciones rotativas durante el 2005 en diversos sitios, entre ellos, el Centro Cultural de la Cooperación y la Universidad de las Madres de Plaza de Mayo. La plaza de México y Jujuy también fue escenario de actividades que hacían referencia a los asesinatos. En el 2009, por ejemplo, La Oruga decide incorporar la plaza como sede de las acciones de protesta que el Frente Popular Darío Santillán estaba coordinando para exigir el procesamiento de los responsables políticos de la masacre y para cambiar el nombre de la estación de ferrocarriles donde ocurrieron los hechos, "Estación Avellaneda", por "Estación Darío y Maxi". La propuesta se basaba en sumarle a las actividades del sábado que ya realizaba el colectivo un recital de rock con grupos musicales del barrio. Para convocar a la actividad una semana antes se realizó en la plaza una instalación titulada "Estación Darío y Maxi". La intervención consistía en un trazado de vías sobre el pasto realizado en cartón. En el extremo de una de las trochas se encontraba el frente de una locomotora diesel, también en cartón, y atado entre dos árboles un cartel con letras blancas sobre cartón negro que decía "Estación Darío y Maxi". En el centro de la plaza se había colocado una cartografía con el recorrido de la línea ferroviaria del Ferrocarril General Roca, marcando especialmente la Estación Dario y Maxi con la frase "No están solos". A un lado de la cartografía colgaba una caja con la inscripción "¿Qué pasó el 26 de junio del 2002?". En el medio de la caja se había practicado una perforación para mirar hacia adentro donde estaba pegada la foto de uno de los dos manifestantes al momento de su asesinato. Toda la instalación estaba encabezada por un cartel de tres metros por uno anunciando la actividad del 20 de junio en la plaza con la leyenda "A siete años de la Masacre de Avellaneda, Darío y Maxi presentes".

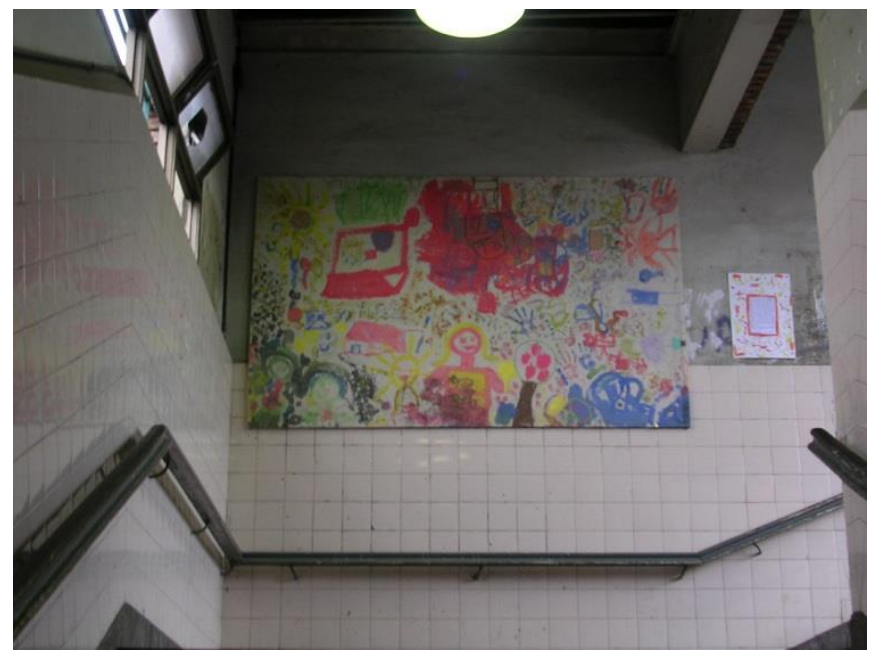

Ilustración 8. Obra colectiva elaborada por los niños del MTD Solano. Expuesta en la estación de trenes Darío Santillán y Maximiliano Kosteki del ramal Roca. 2006.
Otra serie de actividades artístico-culturales se orientaron a problematizar la política estatal de cercamiento de los espacios públicos. Para cuestionar la instalación de rejas en las plazas confeccionamos un telescopio en cartón con barras verticales en uno de sus extremos simulando rejas. Mientras el colectivo desarrollaba sus actividades, dos integrantes del mismo se acercaban a los vecinos invitándolos a mirar la plaza a través del telescopio enrejado. 
Otro integrante de la organización circulaba con una reja personal que colgaba de un sombrero. El sombrero tenía un techo a dos aguas haciendo referencia a la problemática de la vivienda en la ciudad. La composición pretendía denunciar el hecho de que el enrejado de los espacios públicos implicaba la expulsión de las familias en situación de calle que vivían en parques y plazas. A su vez, el hombre enrejado dramatizaba el miedo a la inseguridad sobre el cual se justificaba la política de cercamiento del espacio público. ${ }^{9}$

\section{Entre la política de la estética y la estética de la política}

Como afirmé al comienzo de este trabajo, La Oruga nunca formuló una propuesta estética explícita, por eso las aproximaciones a este terreno a lo largo de los años distan de ser unívocas. Sin embargo, toda la actividad que La Oruga desarrollaba los sábados por la tarde en la plaza de México y Jujuy puede ser comprendida como una ocupación artística del espacio público. En las experiencias reseñadas arriba el arte se incorpora como un elemento más dentro de la acción político-cultural del movimiento. ${ }^{10}$ Junto a la recreación, las instancias educativas y las actividades culturales, el arte estimulaba la creación de nuevas relaciones sociales en el espacio público. El arte en La Oruga resultó un articulador de espacios de encuentro. En esta experiencia multifacética se combina una variedad de procedimientos y de registros. Se trata de un arte que se produce y se recepciona colectivamente, reemplazando las huellas del artista individual por el trabajo de su propio público. Un arte que tiende hacia la "ambientación" (Masotta citado en Longoni, 2004), que se expande en el espacio, tensionando el significado del espacio público. Es un arte que, en consonancia con los objetivos de la organización, promueve la participación y la co-creación a partir de obras inconclusas, como el "Triángulo de la Memoria", o a partir de las instancias de enseñanza y experimentación. Más cerca de las propuestas del arte relacional hoy en boga, que se propone crear situaciones antes que objetos, la actividad artística del colectivo se orientó a la conformación de nuevos lazos sociales.

\footnotetext{
${ }^{9}$ Los usos del espacio público fueron puestos nuevamente en debate en el IV Congreso Internacional de Salud Mental y Derechos Humanos realizado por las Madres de Plaza de Mayo en noviembre del 2005. La Oruga realizó un taller participativo titulado "La construcción de subjetividades en los espacios públicos". El espacio del taller había sido intervenido, definiéndose tres zonas en las cuales una serie de objetos dificultaban el tránsito y la comunicación: un laberinto construido a partir de rectángulos de papel que colgaban desde el techo, un enjambre de hilos que conformaba una suerte de tela araña desordenada, y un conjunto de filas de sillas dispuestas frente a un espejo y tapadas por una gran tela con agujeros para introducir las cabezas de los asistentes. El taller consistía en el desarrollo de una serie de tareas de forma cooperativa. La disposición de los objetos en cada uno de los espacios resultaba un impedimento para el desarrollo de las actividades propuestas obligando a la invención de nuevas formas de comunicación y de organización. Finalmente se cerraba con un debate a partir de las sensaciones que habían experimentado los asistentes.

${ }^{10}$ Otras instalaciones artístico-culturales en el espacio público fueron desarrolladas durante las actividades conmemorativas del Día del Trabajador, del día de la mujer y, desde el 2005, durante los homenajes a las víctimas del incendio del local bailable "República de Cromagnon" ubicado en Balvanera.
} 
Por eso afirmo que el arte en el colectivo no puede entenderse desligado del resto de las actividades que lo acompañaban. En este sentido el arte en La Oruga cuestiona lo que Rancière (2011) denomina "división policial de lo sensible", es decir la correlación fija entre una capacidad y una actividad. La Oruga invitaba a la construcción colectiva de nuevas capacidades, redefiniendo los lugares asignados socialmente. Según Rancière este trabajo de creación de disensos constituye la estética de la política. No obstante, la estética posee una política que le es propia. Las políticas de la estética consisten en las formas en que las prácticas y la visibilidad del arte intervienen en el reparto de lo sensible redefiniendo el espacio de lo común.

En la experiencia estética de La Oruga la autonomía del arte fue atacada sistemáticamente. Las instalaciones incorporaron la estética del shock y apelaron a un público activo. El concepto de obra se desvaneció al fundirse en el espacio público. La burla y el absurdo pretendieron instaurar el distanciamiento crítico de los vecinos frente a su realidad, llamándolos a la participación. Al mismo tiempo la práctica cultural del colectivo operaba extendiendo el territorio liberador del juego y del arte a la vida cotidiana. La política de la estética convivió con la estética de la política en una búsqueda constante por desarticular la correlación entre las capacidades y las actividades determinadas socialmente.

\section{La tensión entre "lo cultural" y "lo político"}

No obstante, en los debates internos siempre existió una preocupación acerca del lugar que le cabía a la política en el trabajo cotidiano. El taller de expresión plástica para niños, que funcionó desde el 2004 hasta el 2009, fue el que alcanzó mayor continuidad. Sin embargo, este espacio, que reconocía un plano artístico más explícitamente, fue percibido en numerosas reuniones internas como una carga, una actividad que dilataba los tiempos del trabajo político. Si logró subsistir a lo largo de los años fue por la valoración de los vecinos. En buena medida las intervenciones estéticas del colectivo eran impulsadas por uno de sus integrantes, un artista plástico y ex militante de organizaciones de izquierda en los años 1970. Los demás integrantes rondábamos los 20/25 años y éramos estudiantes de diversos espacios que poco se relacionaban con el plano artístico. Nos concebíamos a nosotros mismos como una organización política que no lograba trascender el campo cultural. Este diagnóstico alimentó a lo largo de los años un debate recurrente que giraba en torno a las formas en que se podría "incorporar" la dimensión política al trabajo educativo. Si bien la educación, en su vertiente "popular", fue concebida desde los inicios como una práctica pedagógico-política, repetidamente pensamos a la cultura y a la política como esferas escindidas que debían ser puestas en relación. 
Esta voluntad de politización (Gilman, 1997) instauró una inquietud por asegurar una recepción "correcta" del mensaje que circulaba en las actividades. Nos preguntábamos constantemente si la propuesta había sido "comprendida" por los vecinos. Por eso a la

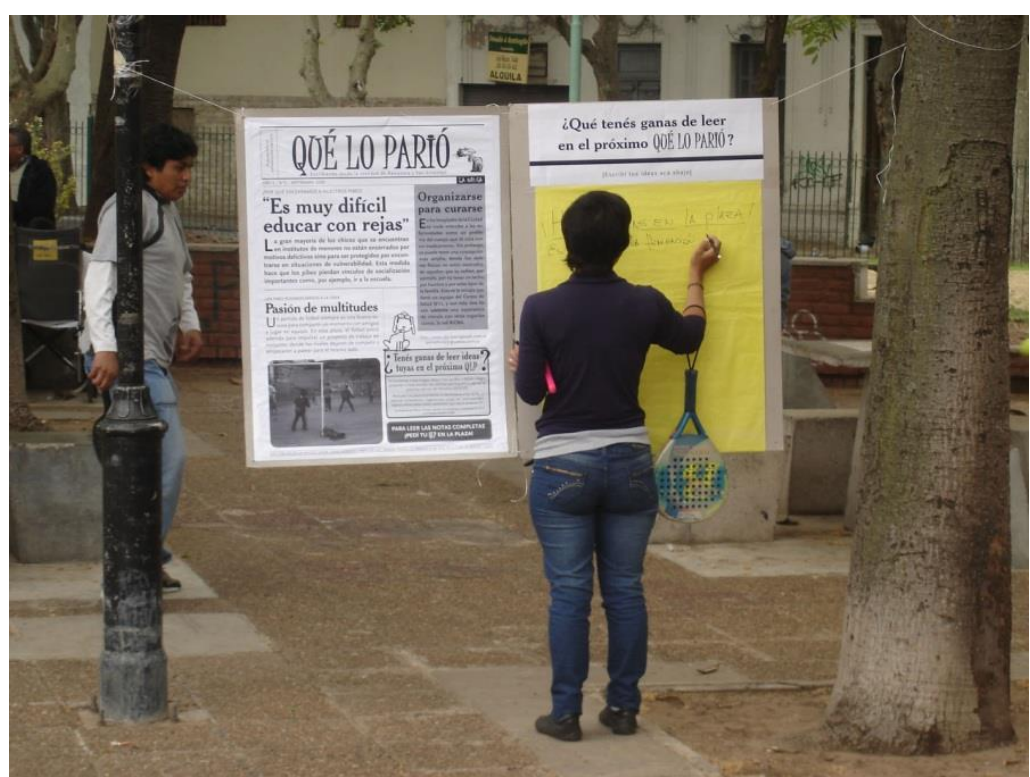

Ilustración 9. Una vecina sugiere contenidos para el periódico "Qué lo parió!" hora de comparar el arte producido por La Oruga con las tendencias del arte contemporáneo podemos encontrar puntos de encuentro, como el sentido lúdico y relacional de las nuevas propuestas, pero no podemos localizar ese rasgo tan característico de la cultura posmoderna como es la apertura hacia la multiplicidad de significados que Danto (1999) sintetiza con el concepto de ambigüedad. Esta preocupación por politizar el arte reservó un lugar central a la voluntad polémica típica del arte crítico, adoptando un tono de denuncia y estableciendo temáticas políticas recurrentes en las producciones artísticas del colectivo.

En buena medida la forma de pensar los procesos estéticos se vio reducida frente a las exigencias políticas de la organización. No obstante, esta preocupación, que hubiera podido derivar en una subordinación absoluta de la cultura a la política, terminó redundando en la búsqueda de formas de intervención estética que incorporasen la dimensión política desde sus propias lógicas. Por eso esta tensión entre el trabajo artístico y las cuestiones estrictamente políticas no terminó anulando el arte, tal como ocurrió en ciertas experiencias latinoamericanas de los años setenta (Gilman, 1997). Antes que una subordinación del "arte" a la "política", esta tensión fue instaurando un espacio estético en el que ambas preocupaciones convivieron productivamente.

¿Cómo explicar esta paradoja? Sostengo que la tensión arte-política pudo ser trabajada creativamente -aunque de forma implícita- gracias a los presupuestos de la educación popular. La búsqueda constante del diálogo con los vecinos para la generación de conocimiento compartido nos obligó a negociar entre nuestros intereses y los de los habitantes del barrio. El proceso de acercamiento hacia la forma de trabajo que el colectivo dio en llamar "recreación popular" en el 2004 es una muestra de este intento: 
"Lo que nosotros llamamos Recreación Popular nace de la práctica y de la mezcla entre nuestras necesidades y las de los chicos con los que trabajábamos durante el 2004. Ellos querían jugar y por eso nos vimos obligados a ver de qué trataba la recreación. Así, poco a poco, ellos y nosotros aprendimos que los juegos transmitían ideas, sentimientos y valores, fundamentales para el proceso educativo. Con un esfuerzo aún mayor comenzamos a ver cómo es eso de que el juego en la sociedad transmite y reproduce las ideas dominantes. Y por eso nos propusimos jugar a otros juegos, a los juegos más cooperativos y menos competitivos, a los más problematizadores y menos pasivos, a los que incluyan a los participantes y no los excluyan, los que varíen las exigencias así no siempre los mejores son los mismos.

Pero con el correr del tiempo fuimos viendo que esos valores (cooperación, solidaridad, integración, etc.) eran funcionales al sistema político, social, económico y cultural dominante. Y pensamos que si nosotros no queríamos ni queremos seguir afirmando este sistema de desigualdad social, teníamos que vincular esos valores a experiencias concretas donde se luche por ellos." (La Oruga,2004).

Lo mismo podemos observar varios años después en el trabajo de producción de "¡Qué lo Parió!" (QLP), el periódico barrial que realizó la organización entre el 2007 y el 2010. La publicación fue pensada como una "aproximación dialógica a la realidad barrial", intentando que el vecino se sintiera identificado con los códigos culturales utilizados.

"...QLP no es un periódico panfletario, ni el órgano de difusión de las actividades de La Oruga. No se trata de estancarse en una posición en cuanto a los distintos temas que puedan tratarse, sino de abrir el juego, el debate, a través de las fisuras que deja el discurso de sentido común que circula por los grandes medios y que tiene eco en la vida cotidiana. Y a partir de ahí

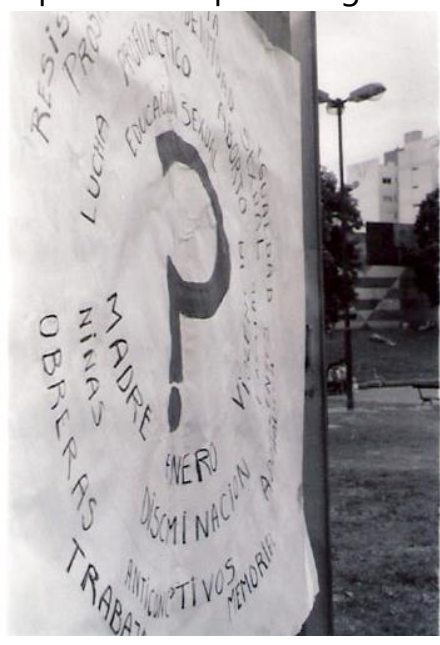

Ilustración 10. Actividad por el día de la mujer. intentar construir conocimiento colectivo desde nuestra realidad, en diálogo con el barrio" (Propuesta del periódico barrial Qué lo Parió para los proyectos UBANEX, 2009).

"Esta es nuestra forma de mostrarnos legítimos, es el modo que encontramos de hablar desde el barrio y no desde una supuesta conciencia prefabricada. Las notas son entonces una mezcla, una negociación a partir del diálogo, entre los vecinos (como realidad construida) y nosotros (como otra construcción).

(...)

...es en la charla, el diálogo y la tensión entre nuestros intereses y los de los demás sujetos (entrevistados-vecinos), donde podemos lograr la mayor efectividad política de la nota, porque

podemos comprender la realidad y las lecturas distintas que están circulando." (Balance anual del periódico barrial Qué lo Parió!, 2008).

La politización de las actividades culturales aparecía como una necesidad de los integrantes del colectivo pero no tenía un correlato directo en las demandas del barrio. 
Muchos vecinos se integraron a la coordinación de los talleres mas muy pocos se acercaron a las reuniones internas en las que se debatían las posiciones políticas de la organización. La negociación resultante entre las necesidades de los vecinos y las de los integrantes de La Oruga configuró el terreno para la emergencia de las formas políticas propias del arte.

A tono con el clima poscrisis del 2001, nosotros buscábamos una ocupación del espacio público que no resultara una "invasión cultural" (Freire, 2002). Se instauró de este modo un arte que podríamos llamar "dialógico", cuyo centro de operaciones resultó ser el espacio público y su orientación fundamental la construcción de nuevas relaciones sociales.

\section{Referencias bibliográficas}

Anderson, P. (1993). "Modernidad y revolución", en: Casullo, N. (comp.). El debate modernidad-posmodernidad, El Cielo por Asalto, Buenos Aires.

Danto, A. (1999). Después del fin del arte. Paidós, Barcelona.

Ellingson, L., y Ellis, C. (2008). "Autoethnography as constructionist project". En: Holstein, A. y Gubrium, J. F. (Eds.). Handbook of constructionist research. New York, Guilford Press, pp. 445-466.

Freire, P. (2002). Pedagogía del Oprimido. Siglo XXI, Buenos Aires.

Gilman, C. (1997). "La situación del escritor latinoamericano: la voluntad de politización". A.A.V.V., Cultura y política en los años '60, Instituto de Investigaciones "Gino Germani"/Oficina de Publicaciones del CBC, UBA, Buenos Aires.

Giunta, A. (2009). Poscrisis. Arte argentino después del 2001. Siglo XXI, Buenos Aires.

Gago, V. (2009). Una época. Cien colectivos. [En línea] Pagina12.com.ar. Disponible en: https://www.pagina12.com.ar/diario/suplementos/las12/13-5102-2009-0816.html [Visitado 7/12/2016].

Longoni, A. (2004). "Vanguardia y revolución en los sesenta". Oscar Masotta, Revolución en el arte. Pop-art, happenings y arte de los medios en la década del sesenta. Edhasa, Buenos Aires.

Longoni, A. y Mestman, M. (1994). "Tucumán Arde: una experiencia de arte de vanguardia en los años sesenta", en Causas y Azares, No 1, primavera, Buenos Aires.

Paredes, D. (2011). "Apuntes sobre arte y política en la Argentina de la última década (2001-2011)." Instituto de Pensamiento Socialista Karl Marx, disponible en Internet: http://www.ips.org.ar/?p=3637.

Rancière, J. (2011). El malestar de la estética. Capital Intelectual, Buenos Aires.

Svampa, M. y Pereyra, S. (2003). Entre la ruta y el barrio. La experiencia de las organizaciones piqueteras. Biblos, Buenos Aires. 
Svampa, M. (2008). "Movimientos sociales y nuevo escenario regional: las inflexiones del paradigma neoliberal en América Latina". Cuadernos de Socio Historia, pp. 1-4.

Zibechi, R. (2003). "Los movimientos sociales latinoamericanos: tendencias y desafíos." OSAL, No 9.

\section{Fuentes documentales}

La Oruga, Colectivo autónomo de educación y recreación popular.

- (2007). Proyecto y balances. 2004 al 2006. Inédito.

- (2007b). Objetivos del colectivo autónomo de educación y recreación popular La Oruga. Inédito.

- (2004). La recreación popular. Inédito.

- (2004-2009) Correos internos.

- (2005-2009) Balances anuales de talleres.

- (2004-2010) Minutas de actividades.

- (2005-2010) Planificaciones.

- (2007-2009) Periódico barrial "Qué lo parió!", 9 números.

- (2009) Propuesta del periódico barrial Qué lo Parió para los proyectos UBANEX. 